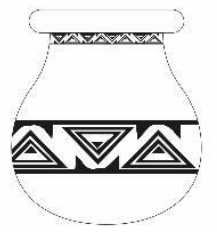

\title{
PALAVRAS E RUÍNAS
}

Ludymylla Maria Gomes de Lucena ${ }^{1}$

Resumo: Esse artigo tem como objetivo refletir, primeiramente, sobre algumas das principais "dificuldades" que o sobrevivente de um evento traumático enfrenta em sua tentativa de representar o passado através do testemunho. Num segundo momento, a literatura e o cinema com teor testemunhal surgem como valiosos documentos históricos na luta contra o esquecimento - a partir do momento que conseguem dar voz aos "sem-nome", aos "esquecidos" pela história oficial e pelas grandes narrativas do século XX. Livros como É isto um homem? e Os afogados e os sobreviventes de Primo Levi e filmes como Shoah de Claude Lanzmann se caracterizam como obras de resistência frente as formas tradicionais de transmissão da palavra. Daí a relevância ética e política dessas obras, cuja força testemunhal fazem da fala, da escrita e do gesto armas para combater o esquecimento, o descrédito e o descaso. Tanto o conceito de "testemunho", como outros conceitos aqui trabalhados, são abordados à luz das discussões de teóricos como como Márcio SeligmannSilva, Jeanne Marie Gagnebin, Walter Benjamin, Giorgio Agamben entre outros.

Palavras-chave: Testemunho; Memória; Literatura; Cinema.

\begin{abstract}
This article aims to reflect, first, on some of the main "difficulties" that the survivor of a traumatic event faces in his attempt to represent the past through testimony. In a second moment, literature and cinema with testimonial content appear as valuable historical documents in the fight against forgetfulness - from the moment they manage to give voice to the "nameless", to those "forgotten" by the official history and the great narratives of the 20th century. Books like Is this a man? and The drowned and survivors of Primo Levi and films such as Shoah by Claude Lanzmann are characterized as works of resistance against traditional ways of transmitting the word. Hence the ethical and political relevance of these works, whose testimonial strength makes speech, writing and gesture weapons to combat forgetfulness, discredit and neglect. Both the concept of "testimony", as well as other concepts worked on here, are approached in the light of discussions by theorists such as Márcio Seligmann-Silva, Jeanne Marie Gagnebin, Walter Benjamin, Giorgio Agamben, among others.
\end{abstract}

Keywords: Testimony; Memory; Literature; Cinema.

\footnotetext{
${ }^{1}$ Doutoranda em Artes pela Universidade Federal do Pará.
} 


\section{REVISTA APOENA - Per. dos Dis. de Fil. da UFPA \\ Belém, 2019, V. 1, N.2.}

\section{Introdução}

Falar, escrever, é, para o deportado que retorna, uma necessidade tão imediata e tão forte quanto sua necessidade de cálcio, de açúcar, de sol, de carne, de silêncio. Não é verdade que ele pode se calar e esquecer. É preciso que, primeiramente, ele se lembre. É preciso que ele explique, que ele conte, que ele domine este mundo o qual ele fora a vítima.

\section{Georges Perec}

Alguns anos após sua radical, polêmica e famosa afirmação de que "escrever um poema após Auschwitz é um ato bárbaro" (1998, p. 26), Adorno, paradoxalmente, parece voltar atrás - ou repensar sobre o seu dito - quando defende, em seu ensaio Engagement, que "o excesso de sofrimento real não permite esquecimento (...) [e que] não há quase outro lugar (se não na arte) em que o sofrimento encontre sua própria voz" (ADORNO, 1973, p. 64).

A partir dos ditos acima podemos perceber que Adorno ao mesmo tempo que se posiciona criticamente frente a uma possível estetização do horror na arte pós-Auschwitz, reconhece a necessidade e o dever de se falar sobre, de não calar.

De um lado então temos a urgência de um pensamento crítico que evite que a gravidade de tal evento se "materialize" em apenas mais um produto cultural "esvaziado" a ser consumido; e de outro, a luta contra o esquecimento via representação artística se tornando necessária para evitar que as catástrofes do século XX se repitam novamente.

O século XX foi um dos períodos mais sangrentos da história da humanidade e que ficará marcado por suas incontáveis atrocidades. Um momento da história apropriadamente chamado pelo historiador Eric Hobsbawm de "A Era dos Extremos"2. Não há meios para se contestar que o século XX deixou um rastro de corpos pelo caminho, como diria Seligmann-Silva:

Nós podemos pensar a humanidade ao longo do século XX como parte de uma sociedade que poderia ser caracterizada, sucessivamente, como pós-massacre dos armênios, pós-Primeira Grande Guerra, pós-Segunda Grande Guerra, pós-Shoah, pós-Gulag, pós-guerras de descolonização, pós-massacres no Camboja, pósguerras étnicas na ex-Iugoslávia, pós-massacre dos Tutsis etc. Mas esse prefixo

\footnotetext{
${ }^{2}$ Cf. HOBSBAWM, Eric. Era dos Extremos. O breve século XX: 1914-1991. São Paulo: Companhia das Letras, 1995.
} 


\section{REVISTA APOENA - Per. dos Dis. de Fil. da UFPA \\ Belém, 2019, V. 1, N.2.}

pós não deve levar a crer, de jeito nenhum, em algo próximo do conceito de "superação", ou de "passado, que passou". Estar no tempo "pós-catástrofe significa habitar essas catástrofes (2005, p. 63).

Todas as situações-limite do século $\mathrm{XX}$ fizeram com que inúmeros indivíduos testemunhassem fatos "inenarráveis", "abomináveis", “inimagináveis". Junto com a dor de ter atravessado tamanho trauma nasce a necessidade e o dever de narrar a experiência vivida. Daí "a centralidade do conceito de testemunho" (SELIGMANN-SILVA, 2005, p. 15) que "coloca-se desde o início sob o signo da sua simultânea necessidade e impossibilidade" (SELIGMANNSILVA, 2003, p. 46).

Esse trabalho tem como foco num primeiro momento visualizar e indicar algumas das principais "impossibilidades” enfrentadas em torno da representação da memória traumática; para num segundo momento identificar tanto na "literatura de testemunho" como no cinema com teor testemunhal um potente meio para dar voz as narrativas do terror frente as ditas "grandes narrativas". Livros como É isto um homem? de Primo Levi e filmes como Shoah de Claude Lanzmann se caracterizam como obras de resistência que fazem da palavra e da fala armas para combater o esquecimento, o descrédito e o descaso. Daí a relevância ética e política do testemunho como forma de enfrentar as formas tradicionais de transmissão da palavra, ou seja, as narrativas que marginalizam e sempre marginalizaram os sem-nome, os esquecidos e todos aqueles que não teriam espaço na história oficial.

\section{Dever de lembrar / necessidade de esquecer}

Após Auschwitz o meio encontrado por muitos dos sobreviventes para dar voz ao seu sofrimento, para tornar pública a experiência traumática passada do Lager foi através da literatura. $\mathrm{O}$ gênero testemunhal ${ }^{3}$ permitiu aos sobreviventes narrar e denunciar os absurdos vivenciados nos

\footnotetext{
${ }^{3}$ Cf. SELIGMANN-SILVA, O local da diferença: “Antes de mais nada, os próprios eventos que estão na base dos discursos sobre o testemunho definem as características que cada um deles assume. Se no âmbito alemão o trabalho de memória em torno da Segunda Guerra Mundial e da Shoah determina em boa parte as discussões, na América Espanhola o ponto de partida são as experiências históricas da ditadura, da exploração econômica, da repressão às minorias étnicas e às mulheres, sendo que nos últimos anos também a perseguição aos homossexuais tem sido pesquisada (...). Em cada uma dessas regiões, as tradições de pensamento que foram mobilizadas para se pensar os conceitos de Zeugnis e testimonio levaram a diferentes contornos da noção de testemunho: se na Alemanha, a psicanálise, a teoria e a história da memória têm desempenhado já há algum tempo um papel central, na América Latina o testimonio é pensado a partir da tradição religiosa da confissão, da hagiografia, do testemunho bíblico e cristão no seu sentido de apresentação de vidas 'exemplares', da tradição da crônica e da reportagem” (2005, p. 81-82).
} 


\section{REVISTA APOENA - Per. dos Dis. de Fil. da UFPA \\ Belém, 2019, V. 1, N.2.}

campos de concentração nazista. Se caracterizando como um instrumento indispensável para recompor esse período. Primo Levi, químico italiano e sobrevivente de Auschwitz, que até então nunca tinha se visto como um escritor, foi um deles. Levi se destacou por narrar, em primeira pessoa, suas memórias a respeito do tempo em que esteve recluso. Suas obras já foram traduzidas para mais de 40 línguas, sendo a principal delas É isto um homem?: um dos testemunhos mais importantes a respeito da rotina do campo de extermínio.

Primo Levi deve ser considerado como um dos autores que levou mais longe e do modo mais acabado a reinscrição testemunhal da catástrofe. A literatura de cunho testemunhal, no entanto, foi e é ainda praticada por inúmeros outros sobreviventes da guerra (e por testemunhas "secundárias", que não vivenciaram diretamente os eventos), tais como Jorge Semprun, Ida Fink, Charlotte Delbo, Jean Améry, Robert Antelme, Tadeusz Borowski, Nelly Sachs e Paul Celan (SELIGMANNSILVA, 2005, p. 78).

Para Levi, testemunhar o que tinha vivido era uma necessidade, um dever ético, uma urgência, mesmo que custasse, mesmo que doesse. Ele confessa no prefácio de $O$ que é isto um homem?: “A necessidade de contar 'aos outros', de tornar 'os outros' participantes, alcançou entre nós, antes e depois da libertação, caráter de impulso imediato e violento, até o ponto de competir com outras necessidades elementares" (LEVI, 1988, p. 8).

Num outro texto cujo título é “Aniversário” essa mesma ideia vem ressaltada quando diz:

Não é lícito esquecer, não é lícito calar. Se calarmos, quem falará? Certamente não os culpados e seus cúmplices. Se não dermos nosso testemunho, num futuro próximo as ações da barbárie nazista, por sua própria enormidade, poderão ser relegadas às lendas. Portanto é preciso falar (LEVI, 2015, p. 66).

Todavia, não podemos falar do dever ético que é lembrar e relatar tal acontecimento, do papel importante que a arte tem nesse contexto, sem mencionar o esquecimento ${ }^{4}$. Não existe memória sem esquecimento. Nietzsche em Genealogia da moral já havia identificado o valor produtivo da capacidade de esquecer. O esquecimento é uma força ativa e o homem, para ele, deveria ser como o animal que necessita esquecer, no qual esquecer é uma força de saúde forte, contra sua faculdade oposta, que é a memória: "imprime-se algo por meio de fogo para que fique na memória somente o que sempre dói” (NIETZSCHE, 2009, p. 60). Esquecer então, para

\footnotetext{
${ }^{4}$ Cf. SELIGMANN-SILVA, História, Memória e Literatura: "Jorge Semprún, que foi liberado de Buchenwald em 11 de abril de 1945, compôs o seu testamento sobre a sua experiência no Lager apenas em 1994. A explicação para esse “atraso: (...) Semprún optara pelo esquecimento. (...) Ele narra em L'écriture ou la vie, 'que não sabia de nada, que nunca soube de nada, eu voltei para a vida. Ou seja, para o esquecimento: a vida era o preço"” (2003, p. 53).
} 


\section{REVISTA APOENA - Per. dos Dis. de Fil. da UFPA}

Belém, 2019, V. 1, N.2.

Nietzsche, garante uma certa harmonia psíquica ${ }^{5}$. Aquele que lembra permanentemente, como Irineo Funes ${ }^{6}$, personagem de Borges ou Górchakov ${ }^{7}$, personagem de Nostalgia, filme de Tarkovsky, adoece.

Logo, seria preciso, seguindo Nietzsche:

Fechar de quando em quando as portas e janelas da consciência (...); fazer silêncio e tábua rasa na nossa consciência, a fim de que aí haja lugar para alguma coisa nova, principalmente para as funções mais nobres para governar, para prever, para pressentir; eis aqui, repito, o ofício desta faculdade ativa, desta vigilante guarda encarregada de manter a ordem psíquica, a tranquilidade, a etiqueta (...). O homem em quem não funciona este complexo aparelho de retenção é um verdadeiro dispéptico, nunca conclui nada... (NIETZSCHE, 2009, p. 57-58)

\section{Representar ou não representar?}

Logo após a Shoah, mesmo que recordar $^{8}$ tenha uma valor ético em si mesmo e se caracterize como uma necessidade e um dever na luta contra o esquecimento, quando se trata de representá-lo, diferentes dificuldades e impossibilidades se apresentam. É válido de nota mencionar algumas delas.

\footnotetext{
${ }^{5}$ Para Bergson (1999), o cérebro realiza uma função muito importante no processo evolutivo quando permite que apenas uma parte da memória se torne consciente, embora todo o passado esteja conservado. Mas por qual razão se torna importante recalcar uma parte de nossas lembranças? Devido a nossa necessidade mais básica de sobrevivência. Nesse sentido, o esquecimento é um processo que age junto com a memória. $\mathrm{O}$ único papel do cérebro e do sistema nervoso, para Bergson, é converter os estímulos em procedimentos práticos. Por isso as lembranças não desaparecem quando o cérebro sofre lesões. O que há é um impedimento da atualização. Como ele diria: "não há nem pode haver no cérebro uma região onde as lembranças se fixem e se acumulem. A pretensa destruição das lembranças pelas lesões cerebrais não é mais que uma interrupção do progresso contínuo através do qual a lembrança se atualiza" (BERGSON, p. 146).

${ }^{6}$ No conto Funes, o memorioso, Jorge Luís Borges nos apresenta o personagem Irineo Funes, que, depois de uma queda do cavalo é acometido de uma doença que lhe confere uma memória infalível. Por tudo lembrar, é impedido de viver o presente e não consegue desenvolver o pensamento crítico (BORGES, 1995).

${ }^{7}$ Em Nostalgia, filme de Tarkovsky, observamos Górchakov, o protagonista, profundamente ligado ao seu passado na Rússia, de modo que sofre devido a uma saudade forte demais e a um sentimento de deslocamento diante da sua vida atual na Itália. Górchakov se sente totalmente desorientado diante de tudo que vê, diante de todas as impressões com que é bombardeado, o que acarreta uma certa incapacidade de incorporar a nova experiência do presente. A própria etimologia da palavra Nostalgia, derivada do grego e composta por Nostos (que significa lar) e Algos (que significa dor), revela a irreversibilidade do tempo, expressa pelo desejo de um passado perdido.

${ }^{8}$ Cf. Dori Laub, citado por Seligmann-Silva em seu texto Literatura e Trauma: um novo paradigma diz: "Existe em cada sobrevivente uma necessidade imperativa de contar e portanto de conhecer a sua própria história, desimpedido dos fantasmas do passado contra os quais temos de nos proteger. Devemos conhecer a nossa verdade enterrada para podermos viver as nossas vidas" (SELIGMANN-SILVA, 2005, p. 70).
} 


\section{REVISTA APOENA - Per. dos Dis. de Fil. da UFPA \\ Belém, 2019, V. 1, N.2.}

Primeiro, o trauma que envolve a recordação do evento. De acordo com Primo Levi "a recordação de um trauma, sofrido ou infligido é também traumática, porque evoca-la dói ou pelo menos perturba: quem foi ferido tende a cancelar a recordação para não renovar a dor; quem feriu expulsa a recordação até as camadas profundas para dela se livrar" (2016, p. 18). É valido de nota que para recordar é preciso, antes de tudo, estar vivo, e só está vivo quem não tateou o fundo do horror, pois, "quem o fez não voltou, ou então sua capacidade de observação ficou paralisada pelo sofrimento e pela incompreensão" (2016, p.12). A possível "testemunha integral" (AGAMBEN, 2008, p. 87) de tal evento, os muçulmanos ${ }^{9}$, eram os prisioneiros totalmente desumanizados. O trauma os acometeu de tal forma que os desfigurou completamente. Agamben afirma que "o muçulmano é o não-homem que se apresenta obstinadamente como homem, e o humano que é impossível dissociar do inumano" (2008, p.87). Levi esclarece:

Não somos nós, os sobreviventes, as autênticas testemunhas (...). Nós, sobreviventes, somos uma minoria anômala, além de exígua: somos aqueles que, por prevaricação, habilidade, ou sorte, não tocamos o fundo. Quem o fez, quem fitou o górgona, não voltou para contar, ou voltou mudo; mas são eles, os 'muçulmanos', os que submergiram - são eles as testemunhas integrais, cujo depoimento teria um significado geral. Eles são a regra, nós, a exceção (LEVI, 2016, p. 18).

Segundo, o risco de sofrer a negação de quem oprime. O gesto genocida vem sempre acompanhado de uma postura de violência contra a memória - memoricídio - a partir do momento em que passa a negar as atrocidades que cometeu no passado. "O genocida sempre visa à total eliminação do grupo inimigo para impedir as narrativas do terror e qualquer possibilidade de vingança” (SELIGMANN-SILVA, 2010. p. 21).

As teses revisionistas são, com efeito, a consequência lógica, previsível e prevista de uma estratégia absolutamente explícita e consciente de parte dos altos dignitários nazistas. Essa estratégia consiste em abolir as provas de aniquilação dos judeus (e de todos os prisioneiros dos campos). A solução final deveria, por assim dizer, ultrapassar a si mesma anulando os próprios rastros da existência (GAGNEBIN, 2006, p. 46).

Vale lembrar Walter Benjamin, em suas teses Sobre o Conceito de História, quando nos alerta afirmando que, quando o inimigo vence, nem mesmo os mortos estão em segurança

\footnotetext{
${ }^{9}$ Essas figuras paralisas, desumanizadas e esvaziadas de vontade que percorriam o Lager eram conhecidas como muçulmanos. Os muçulmanos eram o verdadeiro horror do Lager, algo que não pode ser descrito.
} 


\section{REVISTA APOENA - Per. dos Dis. de Fil. da UFPA \\ Belém, 2019, V. 1, N.2.}

(BENJAMIN, 1994, p. 224-225). Algo certamente previsto pelos próprios perpetradores do genocídio. Sempre preocupados tanto em apagar os rastros dos seus crimes, como em negá-los.

Terceiro, o choque entre a necessidade de narrar a experiência vivida e a irrealidade e inverossimilhança de tal relato. Esse embate entre urgência de narrar e inverossimilhança acaba fazendo com que a vítima que testemunha se veja como "mentirosa", "inventora". De fato, tanto as vítimas como os opressores tinham viva a consciência do absurdo de tudo aquilo que acontecia. Primo Levi recorda um trecho da obra do sobrevivente Simon Wiesenthal (Gli Assassini sono fra noi), onde ele aponta o divertimento e o cinismo dos SS para comunicar aos detentos o futuro amargo que lhes aguardava:

Seja qual for o fim desta guerra, a guerra contra vocês nós ganhamos; ninguém restará para dar testemunho, mas, mesmo que alguém escape, o mundo não lhe dará crédito. Talvez haja suspeitas, discussões, investigações de historiadores, mas não haverá certezas, porque destruiremos as provas junto com vocês. E ainda que fiquem algumas provas e sobreviva alguém, as pessoas dirão que os fatos narrados são tão monstruosos que não merecem confiança: dirão que são exageros da propaganda aliada e acreditarão em nós, que negaremos tudo, e não em vocês. Nós é que ditaremos a história do Lager (LEVI, 2016, p. 7).

Essa mesma consciência do absurdo brotava também, sob a forma de sonho entre os prisioneiros do Lager. No sonho, relatado no prefácio do último livro de Primo Levi, os sobreviventes voltavam para casa e contavam com paixão e alívio seus sofrimentos passados, dirigindo-se a uma pessoa querida, e não tinham crédito ou mesmo eram escutados. Na forma mais típica (e mais cruel), o interlocutor se virava e ia embora silenciosamente (LEVI, 2016).

E quarto, a impossibilidade da tradução total da experiência, ou seja, a insuficiência da linguagem diante dos fatos, como se tal evento-limite, tal horror não pudesse ser representado ou resumido em imagens, palavras, relatos, devendo ficar totalmente de fora da representação. Ainda Levi no capítulo "No fundo" de $O$ que é isto um homem? confessa: "Pela primeira vez, então, nos damos conta de que a nossa língua não tem palavras para expressar esta ofensa, a aniquilação de um homem. Num instante, por intuição quase profética, a realidade nos foi revelada: chegamos ao fundo" (LEVI, 1988, p. 32). Como diria também Simón Srebnik ${ }^{10}$, um dos sobreviventes do campo

\footnotetext{
10 Simón Srebnik era então um garoto de 13 anos quando sobreviveu ao campo de Chelmno. Por muito tempo conseguiu escapar das seleções para a câmara de gás graças a sua bela voz. Com a chegado dos russos em 1945 levou um tiro na nuca a queima roupa, que, contudo, não o matou, sobrevivendo mais uma vez.
} 


\section{REVISTA APOENA - Per. dos Dis. de Fil. da UFPA \\ Belém, 2019, V. 1, N.2.}

de Chelmno que aparece no filme Shoah de Claude Lanzmann: "Ninguém pode descrever isso. Ninguém pode recriar o que aconteceu aqui. Impossível. E ninguém pode entender isso”.

\section{A passagem para o poético}

No geral o século XX foi um período onde houve uma grande preocupação com a questão da memória. "Assistimos a um boom de estudos sobre memória, desmemoria, resgate, tradições" (GAGNEBIN, 2006, p. 97). "Boom de memória" (HUYSSEN, 2000, p. 14) que se concretizou também a partir do florescimento dos julgamentos, das comissões de verdade, da criação de espaços de memória, de museus e de arquivos com acervos públicos, etc. Mesmo diante das "aparentes" dificuldades indicadas acima, no século das catástrofes os trabalhos artísticos em torno da representação da memória se expandem, seja no cinema (Andrei Tarkovsky, Alain Resnais, Chris Marker, Claude Lanzmann), seja nas artes visuais (Rosangela Rennó Anselm Kiefer, Joseph Beuys). Só para mencionar alguns nomes. Teria o sofrimento, pela via artística encontrado a sua voz?

Seligmann-Silva defende a tese de que "só com a arte a intraduzibilidade pode ser desafiada" (2003, p. 47), ou seja, só equipada com a imaginação a insuficiência da linguagem diante dos fatos-limite pode ser enfrentada. Tal tese que vê na passagem para o poético uma via possível para representar o horror põe em cheque a historiografia herdada do positivismo do século XIX, com sua visão de restituir totalmente o passado tal como ele sucedeu. $O$ ato de usar a linguagem para reconstruir o passado restringe a abordagem do discurso historiográfico do presente. Para Benjamin "articular historicamente o passado não significa conhecê-lo 'como ele de fato foi'. Significa apropriar-se de uma reminiscência, tal como ela relampeja no momento de um perigo" (BENJAMIN, 1994, p.224).

O passado não pode ser descrito de maneira factual e não pode ser recuperado em sua integralidade. Desse modo, "a historiografia é apenas uma (re) inscrição do passado e não o 'seu texto original"' (SELIGMANN-SILVA, 2003, p. 74).

$\mathrm{Na}$ Poética de Aristóteles essa relação de diferença entre poesia e história, poeta e historiador é apresentada da seguinte forma:

A tarefa do poeta não é dizer o que de fato ocorreu, mas o que é possível e poderia ter ocorrido segundo a verossimilhança ou a necessidade (...). Um se refere aos eventos que de fato ocorreram, enquanto o outro aos que poderiam ter ocorrido. 


\section{REVISTA APOENA - Per. dos Dis. de Fil. da UFPA \\ Belém, 2019, V. 1, N.2.}

Eis por que a poesia é mais filosófica e mais nobre do que a história: a poesia se refere, de preferência, ao universal; a história, ao particular (ARISTÓTELES, 2015. p. 95-97).

A poesia opera sobre ações que pertencem ao domínio do possível, que corresponde ao "que foi" e ao "que poderia ter sido". A história está restrita ao real, ao "que foi". O historiador narra o que aconteceu. O poeta representa o que poderia acontecer, quer dizer: o que é possível segundo a verossimilhança e a necessidade. Nesse caso, o poeta pode se aproximar do horror mais do que o historiador. A poesia interroga o mundo num nível geral, sendo apta para aproximar-se do impossível, tornando-o verossímil na invenção.

Talvez esteja aí o grande problema com os filmes extremamente realistas que surgiram logo após a guerra. Como Seligmann-Silva diria, nesses filmes “as imagens eram 'reais demais' para serem verdadeiras, elas criavam a sensação de descrédito nos espectadores” (2003, p.57). Ao privilegiarem imagens de arquivo, (muitos deles mostrando cadáveres) tais filmes tentavam seduzir a partir da reprodução mimética do evento-limite, buscando uma catarse através da estetização da violência, do cadáver e da morte, numa ilusória e ousada tentativa de reprodução total e "fiel" do passado, tal qual. Essa reprodução mimética do evento-limite, segundo Seligmann-Silva (2003), só conseguia reproduzir um efeito de irrealidade. "Com relação a esse evento vale o mote: 'Ver para não crer"” (SELIGMANN-SILVA, 2003, p. 94).

\section{SHOAH}

Por outro lado, o filme Shoah, de Claude Lanzmann, afirma a necessidade de se manter a memória viva via privilegio da palavra e não da imagem. É a palavra que comanda ${ }^{11}$. O filme de Lanzmann é todo marcado por entrevistas e por imagens dos campos de concentração, 30 anos depois do final da guerra. Esses espaços aparecem no filme não através de uma reconstituição mimética que trouxesse de volta a imagem do campo tal qual foi, através de um flashback bem montado, ou de imagens de arquivo. O campo surge tal como é hoje, em ruínas, coberto por uma vegetação verde. Lanzmann reconstitui o passado a partir do relato presente, ou seja, a partir do

\footnotetext{
${ }^{11}$ A meu ver o filme Shoah se aproxima esteticamente do documentário cearense Vilas Volantes: o Verbo contra o vento (2005) de Alexandre Veras. Vilas Volantes fala de povos do litoral cearense que são obrigados a migrar por causa da ação dos ventos que movem as dunas da região. Os habitantes/personagens do filme reconstroem através do relato, ou seja, da palavra o passado da vila que já não existe mais.
} 


\section{REVISTA APOENA - Per. dos Dis. de Fil. da UFPA \\ Belém, 2019, V. 1, N.2.}

testemunho vivo dos sobreviventes. Sem grandes espetáculos. Sem nenhum movimento de câmera estetizante ou exibicionista, apenas rostos, palavras e paisagens atuais.

Shoah distancia-se da obscenidade que implica mostrar os cadáveres nas fossas, os restos que não puderam ser eliminados apesar dos esforços da SS, os sobreviventes cadavéricos: imagens gravadas pelos repórteres das tropas britânicas, soviéticas, norte-americanas, depois reconstruídas e que afetaram como um "mal de arquivo" de Nuit et brouillard (1955) de Resnais até The Schindler's list (1992) de Spilberg. Shoah responde com os restos de vozes em ruínas, num "estrépito tardio", mas radical, da palavra (CANGI in SELIGMANNSILVA, 2003, p. 156-157).

A imagem da barbárie surge em Shoah pela voz, pelo gesto, pela postura das testemunhas. Lanzmann capta a expressividade natural do movimento em busca de uma suposta "verdade" do $\operatorname{corpo}^{12}$. (uma verdade da fala).

\section{Memória, testemunho e ficção}

O indivíduo que viveu uma experiência-limite de quase morte busca maneiras de narrar o indizível, de tornar público o que testemunhou. Ele, o sobrevivente mergulha na memória em busca de fragmentos, imagens do acontecimento passado que possam se "estabilizar" por meio do relato - escrito ou falado. Todavia, a memória está permeada de mistérios. Ela é maleável, instável. Para Levi "a memória humana é um instrumento maravilhoso, mas falaz. (...) As recordações que jazem em nós não estão inscritas na pedra; não só tendem a apagar-se com os anos, mas muitas vezes se modificam ou mesmo aumentam, incorporando elementos estranhos" (2016, p. 19).

$\mathrm{O}$ ato de testemunhar batalha continuamente com as dificuldades concernentes à memória e ao esquecimento. Uma vez que não podemos ter acesso ao passado, a possibilidade de se contestar a "verdade" dos relatos testemunhais é real, pois a memória traz o cunho da suspeita. Essa falta de exatidão da memória é o ponto chave no processo criativo da narrativa testemunhal. Quem testemunha a catástrofe traz em seu relato a mistura das incertezas de suas experiências, fazendo com que as lembranças dos fatos vividos, transitem entre o "real" e a "ficção".

\footnotetext{
12 Deleuze, no capítulo Cinema, Corpo, Cérebro e Pensamento em Imagem-tempo fala de um determinado tipo de cinema não mais resultante da história e da narrativa mas dos gestos, posturas e atitudes dos personagens. Cinema dos corpos. "A personagem fica reduzida a suas próprias atitudes corporais, e o que deve sair disso é o gestus, isto é, um espetáculo (DELEUZE, 2007, p. 231).
} 


\section{REVISTA APOENA - Per. dos Dis. de Fil. da UFPA \\ Belém, 2019, V. 1, N.2.}

De acordo com Hartman, "a maioria dos historiadores suspeitam de qualquer modalidade discursiva ou criativa que se desvie do realismo ou de marcos referenciais claros. Eles vêem em uma acuidade positivista a última proteção segura contra o relativismo e o revisionismo" (HARTMAN in SELIGMANN-SILVA, 2000, p. 220). Mas por qual razão? Por o testemunho não conseguir reconstruir o passado tal qual? Mas será mesmo que a veracidade dos fatos históricos pode ser puramente e objetivamente conhecida? De fato, não há como descrever tal acontecimento de maneira literal. O testemunho, por partir da memória - que não existe de todo sem distorções agrega elementos ficcionais. Se eliminarmos esse diálogo entre relato e ficção não há testemunho possível. Jacques Derrida (2004, p. 22) resume essa ideia na seguinte passagem quando diz que "o testemunho está sempre ligado à possibilidade, pelo menos, da ficção, do perjúrio e da mentira" e "eliminada esta possibilidade, mais nenhum testemunho seria possível e não teria mais, em todo o caso, o seu sentido de testemunho".

Ao testemunhar os sobreviventes lidam com a imprecisão de seu relato, logo, a construção imaginativa e criativa na produção do testemunho é inevitável. O testemunho está sob o signo da ficção e não cabe dentro dos limites de um discurso cientificista, positivista e historicista. Ele não tem e nem deve ter um pacto com a "verdade absoluta". Afirmar isso, todavia, não significa dizer que o testemunho seja "relativista", ou que tudo seja "ficção", ou que os testemunhos não tenham legitimidade; mas, significa dizer que os limites entre ficção e "realidade" não podem ser definidos. Seligmann-Silva diria que:

O testemunho encontra-se no vértice entre literatura e a historiografia. Sua ligação com as artes o qualifica para a apresentação do único, mas é também no testemunho que este singular encontra refúgio, diante de uma historiografia voltada para tipificações de épocas e grandes períodos, ou para as 'reduções' economicistas, nacionalistas, etc (2010, p. 93).

$\mathrm{O}$ testemunho flutua entre essas duas linhas. Ele agrega elementos ficcionais e sente uma evidente necessidade de se ater ao "fato", de manter a noção de "fidelidade". Essa cumplicidade entre "ficção" e "fato" tornou possível para os sobreviventes denunciarem as brutalidades ocorridas no século XX. Logo, o testemunho é importante para que o mundo saiba o que aconteceu, pois ele resgata "o que existe de mais terrível no 'real' para apresentá-lo. Mesmo que para isso ele precise da literatura" (SELIGMANN-SILVA, 2003, p. 375).

Mesmo com todas as dificuldades que os sobreviventes enfrentaram para conseguir reelaborar o passado traumático e dar voz as suas narrativas do terror, há ainda o medo da rejeição 


\section{REVISTA APOENA - Per. dos Dis. de Fil. da UFPA \\ Belém, 2019, V. 1, N.2.}

dos possíveis ouvintes ou leitores de seu testemunho. O sobrevivente teme ser visto como “inventor”, teme que seu testemunho caia no descrédito. Por isso é necessário não só narrar a experiência traumática, mas envolver o outro na tentativa de aproximá-lo. Fazer com que o outro encontre também um lugar.

A narrativa teria, portanto, dentre os motivos que a tornavam elementar e absolutamente necessária, este desafio de estabelecer uma ponte com "os outros", de conseguir resgatar o sobrevivente do sítio da outridade, de romper com os muros do Lager. A narrativa seria a picareta que poderia ajudar a derrubar este muro (SELIGMANN-SILVA, 2008, p. 66).

\section{Considerações finais}

Palavras, imagens e gestos. Instrumentos de combate. Pedaços de resistência. Os registros testemunhais, sejam orais ou escritos dinamitam a historiografia tradicional e se concretizam como valiosos documentos históricos no processo de reconstrução da memória, seja da Shoah, seja de qualquer outro evento-limite. É preciso narrar, mesmo que custe.

Mesmo com sua falta de nitidez, mesmo com sua imprecisão, o testemunho tem a capacidade de dar voz aos "restos", as "ruínas", aos "vencidos" e "esquecidos" pela história oficial, muitas vezes manipulada pelo vencedor, por uma única versão ou uma única maneira de ditar, conforme convém.

O testemunho estabelece um pacto contra o esquecimento a partir do relato, a partir da escrita. A luta do sobrevivente não é só contra o trauma, mas também contra a destruição da memória e contra a possível repetição do horror. Apesar do esforço do genocida em apagar os rastros de seus crimes, ocultando a barbárie, é preciso lembrar mesmo que seja do que se quer esquecer. Como diria Gagnebin: "não esquecer dos mortos, dos vencidos, não calar, mais uma vez, suas vozes - isto é, cumprir uma exigência de transmissão e de escritura" (GAGNEBIN, 2006, p. $11)$.

\section{REFERÊNCIAS BIBLIOGRÁFICAS}

ADORNO, Theodor W. Engagement. Notas de Literatura. Celeste Aída Galeão \& Idalina Azevedo da Silva (trad.). Rio de Janeiro: Tempo Brasileiro, 1973. (51-71). 


\section{REVISTA APOENA - Per. dos Dis. de Fil. da UFPA \\ Belém, 2019, V. 1, N.2.}

Prismas: crítica cultural e sociedade. Trad. Augustin Wernet e Jorge Mattos Brito de Almeida. São Paulo: Ática, 1998.

AGAMBEN, Giorgio. O que resta de Auschwitz. São Paulo, Boitempo, 2008.

ARISTOTELES. Poética. São Paulo, Ed. 34. 2015.

BENJAMIN, Walter. Magia e técnica, arte e política: ensaios sobre literatura e história da cultura. Tradução de Sérgio Paulo Rouanet. 7 ed. São Paulo: Brasiliense, 1994.

BERGSON, Henri. Matéria e Memória: ensaio sobre a relação do corpo com o espírito. Trad. Paulo Neves. 2o Ed. São Paulo: Martins Fontes. 1999.

BORGES, Jorge Luis. Funes, o memorioso. In: Ficções. São Paulo: Globo, 1995.

DELEUZE, Gilles. Imagem-tempo. Trad. Eloísa de Araujo Ribeiro. São Paulo: Brasiliense, 2007.

DERRIDA, Jacques. A fita da máquina de escrever. In: Papel-máquina. Trad. Evando Nascimento. São Paulo: Estação Liberdade, 2004.

GAGNEBIN, Jeanne. Marie. Lembrar, escrever, esquecer. São Paulo: 34, 2006.

HOBSBAWM, Eric. Era dos Extremos. O breve século XX: 1914-1991. São Paulo: Companhia das Letras, 1995.

HUYSSEN, Andreas. Seduzidos pela memória: arquitetura, monumentos, mídia. Tradução de Sergio Alcides. Seleção de Heloisa Buarque de Hollanda. 2a. Ed. Rio de Janeiro: Aeroplano, 2000.

NIETZSCHE, F. Genealogia da moral: uma polêmica. Tradução de Paulo C. Souza. São Paulo: Companhia das Letras, 1998.

LEVI, Primo. Os afogados e os Sobreviventes. $3^{\circ}$ ed. São Paulo/Rio de Janeiro: Paz e Terra, 2016. É isto um homem? Trad: Luigi Del Re - Rio de Janeiro: Rocco, 1998.

. DE BENEDETTI, Leonardo; Organização LEVI, Fábio; SCARPA, Domenico. Assim foi Auschwitz: testemunhos 1945-1986. Tradução Federico Carotti. 1. Ed. São Paulo: Companhia das Letras, 2015.

SELIGMANN-SILVA, Marcio. Narrar o trauma. Escrituras híbridas da memória do século XX. In: NOVA, V. \& NOVA, A (orgs.). Ética e Imagem. Belo Horizonte: Arte, 2010. p. 11 - 26.

SELIGMANN-SILVA, M; NESTROVSKI, Arthur. (org.). Catástrofe e Representação, São Paulo, Escuta, 2000.

SELIGMANN-SILVA, M. (org.). História, Memória, Literatura. O testemunho na era das catástrofes. Campinas, Editora da UNICAMP, 2003. 


\section{REVISTA APOENA - Per. dos Dis. de Fil. da UFPA}

Belém, 2019, V. 1, N.2.

. O local da diferença: ensaios sobre memória, arte, literatura e tradução. São Paulo, Editora 34, 2005. 